\title{
LEVERAGING INFORMATION TECHNOLOGY TO BUILD A MORE INCLUSIVE E- SOCIETY
}

\author{
Mysore Ramaswamy, Southern University, Baton Rouge, LA, mysore@acm.org \\ George M. Neely, Sr., Southern University, Baton Rouge, LA, george_neely@subr.edu
}

\begin{abstract}
The last few decades have seen tremendous innovations in information technology (IT) that have affected all aspects of modern life. Contemporary society has been variously called 'Information Society,' 'Digital Economy,' and 'Knowledge Economy.' The term 'E-Society' is perhaps more appropriate as it truly reflects the degree to which we are dependent on electronic or digital means even to execute our daily routine activities. Unfortunately, this convenience has not reached all segments of our society. Globally speaking, only one billon out of six billion has access to the Internet. In the United States, 27 percent of the population lacks access to the Internet, according to a study completed last year by the Pew Internet and American Life Project. In this paper, we analyze the role of information technology in shaping the various aspects of the current e-society. We study the problem from several perspectives and propose a set of recommendations that aids in building a more inclusive e-society.
\end{abstract}

Keywords: Digital Divide, E-Inclusion, E-Readiness, E-Society

\section{INTRODUCTION}

In spite of tremendous innovations in the field of information technology (IT), these benefits have not reached all segments of our society. All governments across the world desire their citizens and businesses to communicate through electronic means for the obvious reasons of efficiency and effectiveness. The number of Internet users has increased exponentially during the last two decades. In spite of this phenomenon, large gaps exist between groups regarding their ability to use information and communication technologies effectively $[4,6,9]$. Digital exclusion may result from a lack of digital literacy, from economic or technical barriers to Internet access, or from a lack of capabilities to use efficiently the new services and facilities linked to information and communication technologies [8]. This digital exclusion results in not benefiting from knowledge resources, the potential of new information and communication services, new job opportunities and better access to employment, and overcoming barriers of distance and mobility.

Much has been written about the potential of information technology to 'revolutionize' society, particularly in the context of their role as catalysts of the 'Information Revolution'. This 'revolution' is often juxtaposed with its predecessor, the Industrial Revolution, usually for the purpose accentuating the idea that communication networks are as integral to the process of development as was the birth and development of industry in the $19^{\text {th }}$ century. While it is the question of access that has risen to the forefront of development agendas in the context of the digital exclusion, much work remains to be done in analyzing and understanding how these technologies are utilized and applied to bring about expected revolutionary societal and economic changes and improvements.

The first challenge to a more inclusive e-society is the need for a robust telecommunication infrastructure that can support all digital communication. Globally speaking, only one billon out of six billion has access to the Internet. In the United States, 27 percent of the population lacks access to the Internet, according to a study completed last year by the Pew Internet and American Life Project. Among those who do have access, about 30 percent still rely on slow dial-up connections. The second and perhaps harder challenge is to mitigate the problem of digital exclusion. The rest of the paper is organized as follows. The next section discusses ereadiness issues. Issues of e-inclusion are discussed in the subsequent section. The conclusions and future research directions are presented in the last section.

\section{E-READINESS ISSUES}

In this section, we study the following two critical components of e-society: digital infrastructure, and interaction content. Digital infrastructure refers to the mechanism through which users access the cyberspace. Interaction content is what drives the users to go online. 
In the early stages, the Internet use relied on dial-up connections that offer limited capacity (56Kbps or less) and intermittent connectivity. The first generation of advanced services with continuous connectivity and expanded capacity (200Kbps to $1 \mathrm{Mbps}$ ) began to be deployed in the latter half of the 1990s. These include DSL services offered over telephone company copper wires, cable modem services offered over cable television facilities, and a small but growing number of wireless services (satellite and terrestrial). However, there are still significant portions of population who do not have access to these services.

Broadband Internet connectivity is viewed as an important part of the infrastructure required to ensure effective e-commerce. The Organization for Economic Cooperation and Development (OECD) states that as of December 2005, the number of broadband subscribers in the United States was $16.8 \%$ (total subscribers: 49,391,060). The breakup is as follows: DSL: $6.5 \%$, Cable: $9.0 \%$, Other: $1.3 \%$. United States ranks $12^{\text {th }}$ among the industrialized countries in the list of broadband subscribers per 100 inhabitants. By ensuring high-speed access and 'always-on' connections, broadband technologies substantially change the patterns of Internet usage [7]. Moreover, whether many of these services should even be classified as 'broadband' has been questioned. The Federal Communications Commission (FCC) defines 'advanced services' as capable of providing more than $200 \mathrm{Kbps}$ on both directions. By that definition, many cable and DSL systems do not qualify, as they are constrained to upstream bandwidths of $128 \mathrm{Kbps}$ or less. At a mere four times the bit rate, $200 \mathrm{Kbps}$ represents only an incremental step from a dial-up modem. Much higher capacity access networks offering services in the 10s to 100 s of Mbps (or more) per household will be needed to fully unleash the full potential of advanced communications infrastructure.

Local governments have the following two important roles to play in the development of broadband infrastructure: (i) financier and (ii) infrastructure developer [2]. Financial incentives can be aimed at stimulating supply, demand, or both. Subsidies to commercial providers can be in the form of outright grants, low-cost loans, or tax incentives. Subsidies to users are typically temporary in nature, or targeted at disadvantaged groups. For example, LaGrange, Georgia gave away WebTV equipment and service for a one year period in an attempt to get more of their socio-economically citizens online [5]. Unfortunately, the attempt was largely unsuccessful, reflecting barriers to adoption that go beyond the cost of access, as well as unpopular limitations of the chosen technology - the WebTV devices used had no print capability. Broadband related subsidies appear to be more common at state and federal levels, where budgets are significantly large. For example, Pennsylvania administers a \$3.3million digital divide grant program based on federal funds from the Temporary Assistance to Needy Families (TANF) program. One of their grants was $\$ 457,000$ to the Glendale School District (located in economically disadvantaged area) to extend wireless broadband Internet access from one school to neighboring schools as well as citizens, and to give laptops to community members who partake of training opportunities [3].

The other strategy that local governments can pursue to stimulate broadband is to develop one or more aspects of the necessary infrastructure themselves. Based on an assessment of the communications needs and existing resources available to different groups of users, government can prioritize infrastructure developments for itself, local businesses, and citizens. A local government can deploy a network for its own needs, and later exploit any excess capacity to offer services to nearby businesses.

Wireless networks add their own complexity to the mix. Last year, Google while testing its first municipal Wi-Fi network in its hometown, Mountain View, Calif., using transmitters attached to street lamps, observed that people using Google's network could get online at home only by holding their laptops against a window. This was to be expected as using municipal Wi-Fi for residential coverage was "the equivalent of expecting street lamps to light everyone's homes.”

The second critical component of e-society refers to the digital content that users can access User interactions with digital or electronic means have been grouped in a number of ways [11]. In the present analysis, it will be useful to categorize them in the following way: information services, communication services, and transaction services. A more inclusive e-society has to provide more useful digital interactions to a larger segment of the society, especially in the third category of transaction services.

In the context of e-inclusion, under the category of transaction services, government-to-citizen interactions of e-Government become very significant. In order to build a more inclusive esociety, we need to address these questions: 
- How can we make e-Government truly citizencentric?

- Do we have objectives that are correct and realistic?

- How well are we achieving these objectives fully and cost effectively?

- Are these objectives jointly determined and agreed upon by the citizens and the government agencies?

We need better models of the processes used to plan, fund, develop, implement, operate, and evaluate successful e-Government in various political and social, cultural, and economic contexts [1].

Some of the above concerns are addressed by the eGovernance cube. Ramaswamy and Selian [10] propose the formation of an e-Governance cube with the following three axes: entity type on the x-axis, processing complexity on the $\mathrm{y}$-axis, and perceived value on the z-axis. The e-governance cube provides a means of evaluating an extensive (if not comprehensive) series of government-constituent interactions. Depending upon which of the 27 subcubes contains the given transaction of interest, we are now able to make inferences on the potential of that transaction for its ease of conversion to egovernance. This naturally opens up a wide arena of analysis, particularly for others who wish to specialize and focus specifically on the dynamics and characteristics of specific e-governance transactions. In the context of the e-governance cube model, the further one moves away from the origin, the more resistance one encounters. From the e-inclusion view point, the processes that are valued high on the $\mathrm{z}$-axis (perceived value) need to be addresses first.

\section{E-INCLUSION ISSUES}

The objective of 'E-inclusion' is to end the digital divide, a term used to describe the fact that the world can be divided into people who do and people who don't have access to - and the capability to use modern information technology (IT). According to advocates, e-inclusion has the power to: close the gap between developed and less developed countries; promote democracy and mutual understanding; and empower disadvantaged individuals, such as the poor, the disabled, and the unemployed.

An increasing number of computer equipment and software companies have e-inclusion programs. According to Hewlett-Packard, the purpose of their einclusion initiative is "... to close the gap between the technology-empowered communities and the technology-excluded communities on our planet by making it profitable to do so." The company's program is targeting low-income areas in the developing world to improve opportunities for education, healthcare, and employment and deliver access to world markets and consumer credit.

Recent studies of the digital divide confirm that the user education and skills are discriminating factors in the use of e-services. They also indicate that the 'access divide' is narrowing [8]. The effective use of e-services relies on relies on cumulative skills developed through the use itself (cognitive and social resources). The 'second order' digital divide refers to the ability to deal with continuous evolution and changing complexity of e-services.

To attract technology shy or resistant people, awareness campaigns should be expanded in communities at risk of digital exclusion, communicating the specific benefits for disadvantaged people, and using channels that are appropriate for their way of life. Awareness measures should be designed as a first step in an integrated einclusion strategy, followed-up by incentives for access and training. Information and communication technology (ICT) producers, information providers and government authorities should be sensitized to the special needs of disadvantaged people in terms of ICT equipment and online content and in terms of opportunities for removing barriers for work.

Some of the other broad range issues emerging in the context of e-inclusion are:

- demand-related issues such as lacking motivation among particular population groups to utilize online services for one's own improvement;

- supply-oriented issues such as lack of recognition of specific requirements certain population groups may have with the services offered; and

- regulation-related issues such as restricted availability of the required technical infrastructure (access networks, terminals) among particular population groups.

\section{CONCLUSION}

Innovations in information and communication technologies have rendered electronic means of interactions so ubiquitous that we are indeed living in an e-society. However, some sections of our population do not seem to be fully exploiting the available technology. Broadband availability and appropriate digital content are some of the factors 
that have become obstacles in building a more inclusive e-society.

To tap the e-society's potential for disadvantaged people, the following recommendations are offered:

- develop quality checks of responses of public web sites to special needs of disadvantaged people;

- stimulate online activities in the voluntary and non-profit sector;

- include ICT literacy of low-income and loweducated workers in the employment guidelines;

- match online recruitment services with the needs of workers with special needs;

- explore the opportunities of digital TV and mobile communications for e-inclusion purposes.

\section{REFERENCES}

1. Carbo, T. and Williams, J. (2004). Models and Metrics for Evaluating Local Electronic Government Systems and Services. The Electronic Journal of Electronic Government, Vol. 2, No. 1, pp. 99-106.

2. Clark, K. and Baker, P. (2003). Municipal Advanced Telecommunication Infrastructure Project (MuniTIP). Georgia Center for Advanced Telecommunications Technology, OTP Policy Study No. 50103.http://www.gcatt.org/otp/papers/

MuniTIP.pdf

3. Government Technology. (2002). Pennsylvania Targets Digital Divide. http://www.govtech,net/news.news.phtml?doci $\mathrm{d}=2002.1209 .33355$

4. Hopkins, L. (2005). Making a community network sustainable: The future of the wired high rise, Information Society, 21 (5), 379.

5. Keil, M. et al. (2003). Bridging the Digital Divide: The Story of the Free Internet Initiative in LaGrange, Georgia. Proceedings of the $36^{\text {th }}$ Hawaii International Conference on Information Systems, (10 pages).

6. Koss, F. A. (2001). The Challenges of redressing the digital divide, Journal of International Affairs, 55 (1), 75-90.

7. Lee, H. et al (2003). The growth of broadband and electronic commerce in South Korea: Contributing factors, Information Society, 19 (5), 81-93.

8. Mason, S. M. et al (2003). Applying communication theory to digital divide research, IT and Society, 1 (5).
9. Mistry, J. J. (2005). A conceptual framework for the role of government in bridging the digital divide, Journal of Global Information Technology Management, 8 (3), 28-46.

10. Ramaswamy, M. and Selian, A. (2007). eGovernment in Transition Countries: Prospects and Challenges, Proceedings of the $40^{\text {th }}$ Hawaii International Conference on Information Systems, (10 pages).

11. Turban, E. et al, Electronic Commerce: A Managerial Perspective, Prentice Hall, Upper Saddle River, NJ, 2004. 